\title{
EQUIPMENT
}

UDC 666.1.031

\section{MODELING OF THE THERMAL OPERATION OF A HIGH-CAPACITY GLASSMAKING FURNACE}

\author{
V. Ya. Dzyuzer, ${ }^{1,2}$ V. S. Shvydkii, ${ }^{1}$ and E. B. Sadykov ${ }^{1}$
}

Translated from Steklo i Keramika, No. 9, pp. 23 - 27, September, 2012.

\begin{abstract}
The results of mathematical modeling of the thermal operation of a 280 tons/day glassmaking furnace with a horseshoe flame are presented. It is shown that specific extraction of molten glass $2.5 \mathrm{tons} /\left(\mathrm{m}^{2} \cdot\right.$ day $)$ and specific heat flow $4563.8 \mathrm{~kJ} / \mathrm{kg}$ with gas heating of the furnace can be attained without additional electric heating of the melting tank.
\end{abstract}

Key words: glassmaking furnace, mathematical modeling, heat-and-mass transfer, energy efficiency.

The modern methods of designing glassmaking furnaces include mathematical modeling of the thermal work of a furnace. The difficulty in developing new furnace designs stems from the need to perform a detailed analysis of external and internal heat-and-mass transfer processes, which by their physical nature are not only coupled but also mutually dependent to a considerable degree [1].

Neither the heat balance of a furnace nor calculations of its individual structural parts reveal the coupled character of the thermal processes involved in glassmaking. Moreover, local methods of performing calculations do not permit determining the effect of the boundary conditions of forced convection of the melt on internal heat transfer and the structure of the convection flows in the melting tank. The temperature of the molten glass at the entrance into the neck of a glass furnace, which is the main boundary condition for calculating the extraction channel of furnace, remains undetermined. Of definite practical interest is the temperature distribution on the inner surfaces of the refractory masonry. These and other problems can be solved by mathematical modeling of the thermal operation of furnaces using coupled numerical models of the internal and external heat-and-mass transfer $[2,3]$.

We shall examine the modeling results obtained for a glassmaking furnace with a horseshoe flame for melting container glass. The furnace design implements a number of

\footnotetext{
1 First President of Russia B. N. El'tsin Urals Federal University, Ekaterinburg, Russia.

2 E-mail: vdzuzer@yandex.ru.
}

novel technical solutions. In combination they secure not only high glassmaking efficiency but also the possibility of making colored as well as colorless glass. In addition, even though the specific production 2.5 tons $/\left(\mathrm{m}^{2} \cdot\right.$ day $)$ of molten glass is high, the furnace design does not provide for additional electric heating of the melting tank.

The nominal energy efficiency of glassmaking $(1090 \mathrm{kcal} / \mathrm{kg})$ is attained by optimizing the organization of the flame and the high additional heating temperature of the air and minimizing the heat losses into the surrounding medium. The construction of the burner ensures that the conditions required for directed forward radiant heat transfer and fuel burnup in the range $70-80 \%$ of the length of the working space of the furnace are created.

Efficient heat-insulating materials are used for the crown and walls of a once-through regenerator. In consequence, the heat losses through the regenerator's masonry do not exceed $5 \%$ of the heat content of the products of combustion. The in-

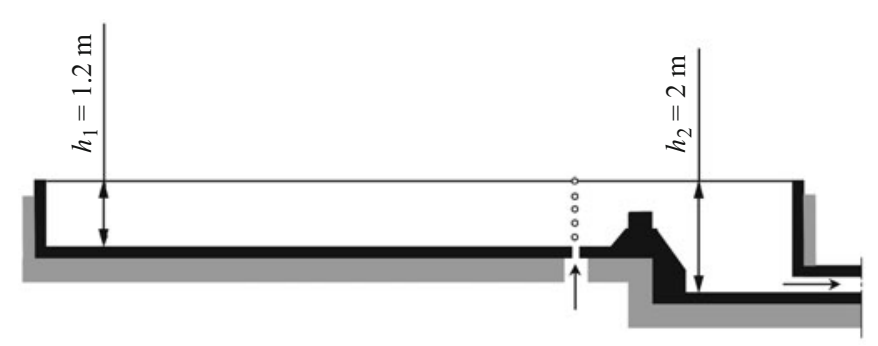

Fig. 1. Diagram of melting tank. 


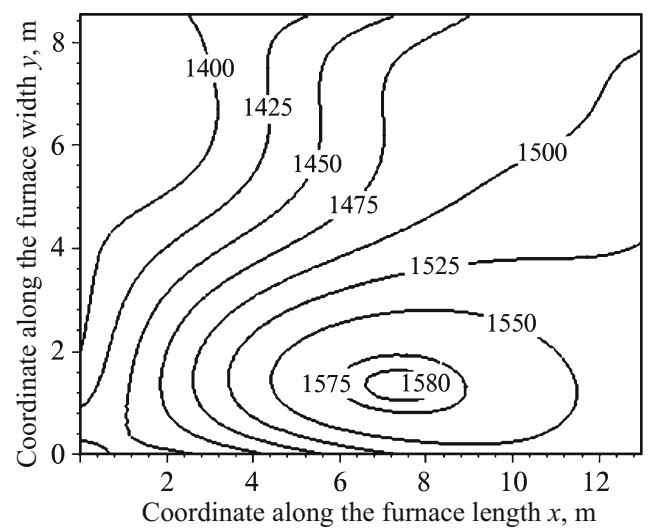

Fig. 2. Temperature field of the surface of the roof.

ternal volume of the regenerator is filled with TL 14/15 pot-type elements. The specific surface area of heating of the charge is $45 \mathrm{~m}^{2} / 1 \mathrm{~m}^{2}$ of the melting tank. As a result, the temperature of the exhaust gases at the exit from the checker is about $300^{\circ} \mathrm{C}$, while the nominal amount of additional heating of the air for combustion is greater than $1300^{\circ} \mathrm{C}$.

\section{Technical Characteristics of a Furnace}

Capacity, tons/day $(\mathrm{kg} / \mathrm{sec}) \ldots . . . . .280$ (3.24)

Specific molten-glass output, tons $/\left(\mathrm{m}^{2} \cdot\right.$ day $) \ldots . . .2 .5$

Fuel . . . . . . . . . . . . . Natural gas

Lowest working heat-generation capacity

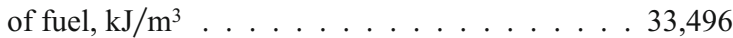

Air heating temperature in regenerator, ${ }^{\circ} \mathrm{C}$. . . . . . 1300

Gas flow to melting, $\mathrm{m}^{3} / \mathrm{h} \ldots \ldots$. . . . . . . . 1590

Specific heat flow to glassmaking, $\mathrm{kJ} / \mathrm{kg}$. . . . . . 4563.8

Maximum furnace roof temperature, ${ }^{\circ} \mathrm{C}$. . . . . $1580 \pm 10$

The results obtained in [5] were used to design the furnace weirs in the melting part of the furnace. The use of energy-efficient masonry made it possible to reduce the heat losses into the ambient environment to $7 \%$ of the consumption part of the furnace heat balance.

Special attention was devoted to the calculation and design of the melting tank. The configuration solutions for the tank profile are based on previously established and mathematically formalized laws of hydrodynamics and internal heat transfer [6].

The scheme of the melting tank with melting and fining zones of variable depth separated by an overflow weir (Fig. 1) is well known in the glass industry and widely used in furnace design. At the same time its efficiency manifests only with a certain combination of geometric dimensions of the melting and fining zones, of which the most important are the height of the dam and neck as well as the length and depth of the pit after the dam. Of fundamental importance for forming a flow with a rational two-cycle structure in the tank is the degree to which these parameters match the boundary conditions for free (natural) and forced convection [1].

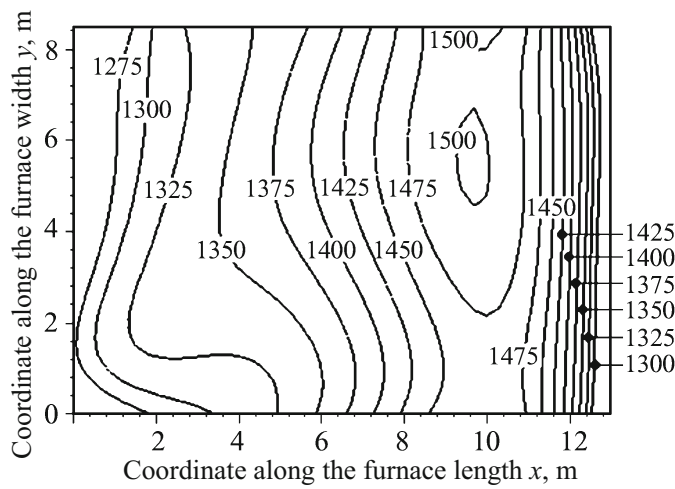

Fig. 3. Temperature field of the surface of the molten glass.

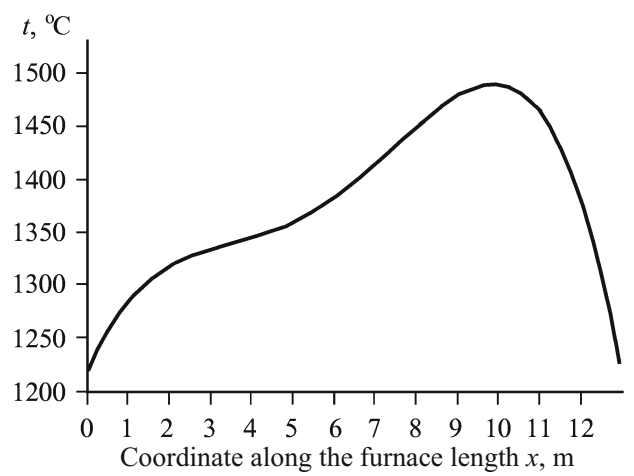

Fig. 4. Variation of the surface temperature of molten glass averaged over the length of the furnace.

A preliminary calculation of the melting tank is done using free-convection boundary conditions prescribed by the temperature distribution on the surface of the molten glass [7]. At this stage the depth of the melting and fining zones as well as the structure of the masonry of the side walls and bottom of the tank are calculated.

In accordance with the concept of building a coupled mathematical model of the thermal operation of a glassmaking furnace [1], the temperature field on the surface of the molten glass is determined by the external heat transfer in the working space. In the article the results of modeling the external heat transfer are presented by the temperature fields of the roof (Fig. 2) and molten glass (Fig. 3).

Analysis of the data in Fig. 2 shows that the maximum heating temperature of the roof is $1582.2^{\circ} \mathrm{C}$. This corresponds to the conditions of long-time operation of the heatinsulating silica roof [1].

The average temperature of the roof is $1485.8^{\circ} \mathrm{C}$.

The surface heating of the molten glass (see Fig. 3) is characterized by a relatively uniform temperature distribution over the width of the tank in the melting zone. Even greater uniformity of the heating is observed in the fining zone (after the dam). The distribution along the furnace length of the tank-width average of the surface temperature of the molten glass (Fig. 4) corresponds to the conditions for 
TABLE 1. Parameters of Heat Transmission through the Melting Tank of the Furnace (Dark-Green Glass)

\begin{tabular}{lccccc}
\hline \multirow{2}{*}{ Parameter } & \multicolumn{2}{c}{ Melting zone } & & \multicolumn{2}{c}{ Fining zone } \\
\cline { 2 - 3 } \cline { 5 - 6 } & $\begin{array}{c}\text { Free } \\
\text { convection }\end{array}$ & $\begin{array}{c}\text { Forced } \\
\text { convection }\end{array}$ & & $\begin{array}{c}\text { Free } \\
\text { convection }\end{array}$ & $\begin{array}{c}\text { Forced } \\
\text { convection }\end{array}$ \\
\hline$h, \mathrm{~m}$ & 1.2 & 1.2 & & 2.0 & 2.0 \\
$\bar{t}_{\mathrm{mg}},{ }^{\circ} \mathrm{C}$ & 1373.7 & 1373.7 & & 1391.1 & 1391.1 \\
$\bar{t}_{\mathrm{b}},{ }^{\circ} \mathrm{C}$ & 1305.2 & 1317.2 & & 1279.4 & 1338.9 \\
$\bar{t}_{\text {ext }},{ }^{\circ} \mathrm{C}$ & 95.2 & 95.7 & & 94.0 & 96.7 \\
$\bar{R},\left(\mathrm{~m}^{2} \cdot \mathrm{K}\right) / \mathrm{W}$ & 2.00 & 1.89 & & 2.09 & 1.88 \\
$\bar{K}, \mathrm{~W} /\left(\mathrm{m}^{2} \cdot \mathrm{K}\right)$ & 0.4784 & 0.5058 & & 0.4596 & 0.5085 \\
$\bar{q}, \mathrm{~W} / \mathrm{m}^{2}$ & 638.0 & 646.0 & & 621.0 & 660.5 \\
\hline
\end{tabular}

Notations: $h$ ) thickness of glass layer; $\bar{t}_{\mathrm{mg}}$ ) average temperature of the molten-glass surface; $\bar{t}_{\mathrm{b}}$ ) average temperature of the melt at tank bottom; $\bar{t}_{\text {ext }}$ ) average temperature of the exterior surface of tank bottom; $\bar{R}$ ) average coefficient of thermal resistance; $\bar{K}$ ) average coefficient of heat transfer through the masonry; $\bar{q}$ ) average heat flux into the ambient environment.

the formation of two-cycle structure of the convection flows [1]. The temperature maximum lies at a distance from the entry wall equal to 0.75 of the length of the melting tank. To fix the position of the hotspot along the tank a row of bubbling nozzles is placed precisely at this location. We note that the average $\left(1380.4^{\circ} \mathrm{C}\right)$ and maximum local $\left(1502.5^{\circ} \mathrm{C}\right)$ surface temperatures of the molten glass correspond to the conditions of high-temperature melting of glass.

Analysis of the surface temperature field of the molten glass makes it possible to determine the boundary temperatures in order to calculate the melting tank. The average surface temperatures of the tank in the melting (before the dam) and fining zones are 1373.7 and $1391.1^{\circ} \mathrm{C}$, respectively. Under these conditions and in the absence of glass extraction the melt temperatures at the tank bottom are 1305.2 and $1279.4^{\circ} \mathrm{C}$ (Table 1), respectively. This temperature level attests to the high efficiency of the heat insulation of the bottom, which is confirmed by the very low heat losses into the ambient environment. For the melting and fining zone $\bar{q}=638.0$ and $621.0 \mathrm{~W} / \mathrm{m}^{2}$, respectively.

The real picture of the convective motion of melt in the tank can be obtained by taking account of the boundary conditions for forced convection. The streamlines, whose tangents indicate the direction of the velocity vector at the points of tangency, give a graphic picture of the instantaneous flow pattern. For steady flow the streamlines are also the trajectories of the motion of the medium.

The melt flow in the melting tank is represented by a two-dimensional field of relative flow lines (Fig. 5). The streamlines are normalized to the mass flow of the glass through the neck, which equals $3.24 \mathrm{~kg} / \mathrm{sec}$ for the prototype. The magnitude of the relative streamlines characterizes the number of times the molten glass circulates in the corre-

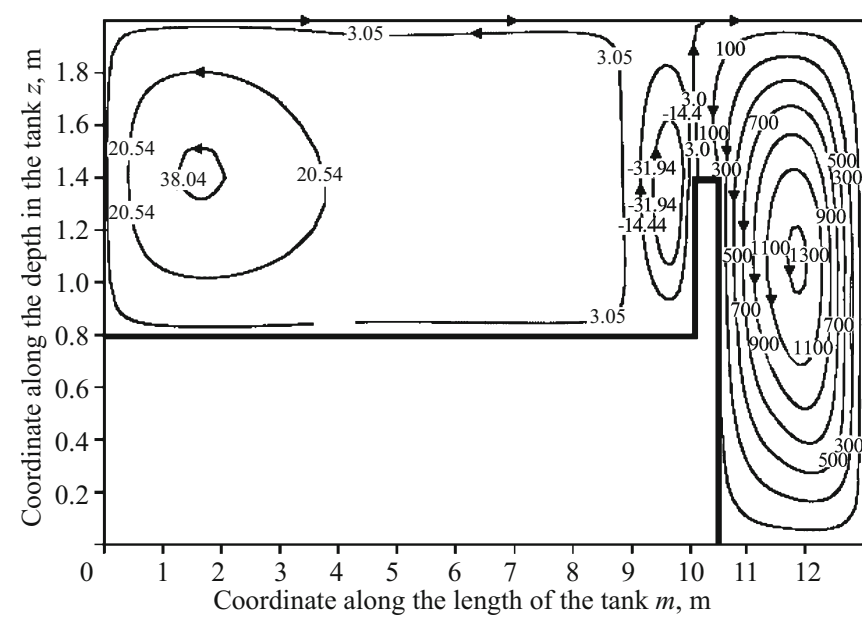

Fig. 5. Flow pattern of the molten glass in the melting tank (the stream functions are normalized to the flow rate of the melt through the neck).

sponding rotational contours. It should be noted that there is a large difference of the intensity of the motion of the molten glass between the melting and fining zones. For this reason, the scale of the image for these zones of the melt tank is changed in order to clearly visualize the calculations.

On the left-hand side of the tank (before the dam) there are two centers of circulation in the flow of the molten glass; the circulation multiplicity factor is 49.8 in the left-hand and 16.54 in the right-hand center (it is not manifested in Fig. 5). On the whole the melt in the melting zone rotates counterclockwise: from left-hand wall to the dam along the bottom of the tank and to the left-hand wall from the dam in the subsurface layer.

Because the melt flow breaks off on the top edge of the weir a small contour of very intense circulation forms on left-hand surface of the dam with circulation multiplicity -82.2 at the center (the minus sign indicates clockwise rotation). Finally, after the dam there is a single center of very intense circulation with multiplicity 1633.9.

The high circulation multiplicity of the molten glass after the dam promotes averaging of the melt temperature in the fining zone. In consequence, the coefficient of thermal uniformity of the molten glass at the exit from the melting tank reaches $99.3 \%$. The temperature of the glass at the entry into the dam is $1343.9^{\circ} \mathrm{C}$.

As a result of the intensification of convective heat transfer from the high-temperature fining zone into the batch loading zone the temperature of the melt layer at the bottom on this section of the tank (Fig. 6) is higher than at the surface of the tank (see Fig. 4). On the whole the average values of the bottom temperature of the molten glass in the melting and fining zones increase to 1317.2 and $1338.9^{\circ} \mathrm{C}$, respectively (see Table 1). It should be noted that the temperature level indicated is reached, as a rule, with additional electric heating of the melting tank with power $1000 \mathrm{~kW}$. Rationalizing the design of the melting tank and optimizing external 


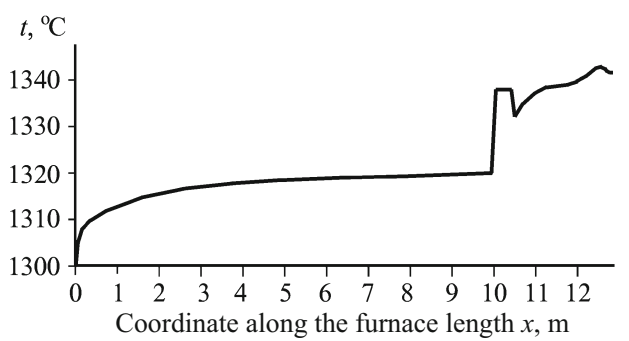

Fig. 6. Variation of the melt temperature at the bottom of the melt tank.

heat transfer make it possible to eliminate losses due to the installation and operation of an auxiliary electric heater.

In closing we can state that the mathematical modeling supports the validity of the design adopted for the furnace. It attests to the possibility of high-capacity energy-efficient glassmaking without an auxiliary electric heater.

\section{REFERENCES}

1. V. Ya. Dzyuzer and V. S. Shvydkii, Design of Energy-Efficient Glassmaking Furnaces [in Russian], Teplotekhnik, Moscow (2009).

2. V. Ya. Dzyuzer, V. S. Shvydkii, and E. B. Sadykov, "Numerical model of external heat transfer in a gas-electric glassmaking fur- nace," Steklo Keram., No. 2, 8 - 13 (2012); V. Ya. Dzyuzer, V. S. Shvydkii, and E. B. Sadykov, "Numerical model of external heat exchange in a gas-electric glassmaking furnace," Glass Ceram., 69(1 - 2), $44-49$ (2012).

3. V. Ya. Dzyuzer and V. S. Shvydkii, "Mathematical model of the hydrodynamics of the melting tank of a glassmaking furnace," Steklo Keram., No. 1, 3 - 8 (2005); V. Ya. Dzyuzer and V. S. Shvydkii, "Mathematical model of hydrodynamics of the glass-melting tank," Glass Ceram., 62(1 - 2), 3-8 (2005).

4. V. Ya. Dzyuzer, "Methods of increasing the energy-efficiency of glassmaking furnaces," Steklo Keram., No. 1, 11 - 14 (2012); V. Ya. Dzyuzer, "Methods of increasing the energy-efficiency of glass furnaces," Glass Ceram., 69(1 - 2), 12 - 15 (2012).

5. V. Ya. Dzyuzer, V. S. Shvydkii, and E. B. Sadykov, "Boundary conditions for heat transfer through the masonry of a glassmaking furnace," Steklo Keram., No. 5, 28 - 33 (2012).

6. V. Ya. Dzyuzer and V. S. Shvydkii, "Effect of the melting tank design on the heat transfer and hydrodynamics of melt in a glassmaking furnace with a horseshoe-shaped flame," Steklo Keram., No. 10, 9 - 16 (2006); V. Ya. Dzyuzer and V. S. Shvydkii, "Effect of the melting tank design on the melt heat exchange and hydrodynamics in a glass-making furnace with horseshoe-shaped flame direction," Glass Ceram., 63(9-10), 326-333 (2006).

7. V. Ya. Dzyuzer, "Calculation and design of the melting tank of container-glass furnaces," Steklo Keram., No. 11, 3 - 8 (2009); V. Ya. Dzyuzer, "Calculation and design of melting tanks for glassmaking furnaces for container glass," Glass Ceram., 66(11 - 12), $369-374$ (2009). 